\title{
Attitudes and Social Norms Are Related to Attendance at Childhood Obesity Prevention Classes in a Rural Mexican- Heritage Community
}

Lucia L. Kaiser, PhD, $\mathrm{RD}^{1}$; Banafsheh Sadeghi, PhD, $\mathrm{MD}^{2}$; Iraklis E. Tseregounis, $\mathrm{PhD}^{3}$; Rosa D. Manzo, $\mathrm{PhD}^{4}$; Lisa Martinez, $\mathrm{PhD}, \mathrm{RN}^{5}$; Maria I. Rangel, $\mathrm{MPH}^{6}$; Rosa Gomez-Camacho, $\mathrm{PhD}^{3}$; Sara Schaefer, $\mathrm{PhD}^{3}$; Adela de la Torre, $\mathrm{PhD}^{3}$

\begin{abstract}
Objective: To examine factors related to attendance of Mexican-heritage parents at community-based nutrition classes to prevent childhood obesity.

Methods: Starting in 2011, interviewers collected baseline data from Niños Sanos Familia Sana (Healthy Children, Healthy Families) participants in rural California. Educators maintained attendance logs from 2012 to 2014. Informed by the Theory of Planned Behavior, interviewers administered an exit survey in 2015 to collect data on attitudes, subjective norms, health motivations, and perceived control related to attendance. Multivariable ordinal logistic regression analysis examined the correlates of attendance $(n=194$, intervention group only).

Results: Controlling for mother's age, marital status, acculturation, and employment, attitudes and subjective norms were significantly related to attendance (odds ratio $=1.27 ; 95 \%$ confidence interval $[\mathrm{CI}]$, $1.18-1.37 ; P<.001)$.

Conclusions and Implications: In these Mexican-heritage participants, attitudes and subjective norms were significant correlates of attendance. The Theory of Planned Behavior may shed light on attendance of high-risk groups but further testing of instruments is needed.
\end{abstract}

Key Words: attendance, childhood obesity prevention, Latino, nutrition education classes, parents ( $J$ Nutr Educ Behav. 2018;50:824-828.)

Accepted May 7, 2018. Published online July 10, 2018.

\section{INTRODUCTION}

The prevalence of obesity is higher in Latino $(21.9 \%)$ than non-Latino white children (14.7\%). ${ }^{1}$ Although family-based approaches have been effective in reducing child obesity in Latinos, ${ }^{2-4}$ inconsistent attendance can inhibit success. ${ }^{5-7}$ Whereas others have reported attendance patterns, ${ }^{2,4}$ to the current authors' knowledge, no study has examined factors related to Latino attendance specifically in childhood obesity interventions. In other health-related studies, participant's age, education, income, gender, and household size are associated with attendance. ${ }^{8,9}$ Factors negatively affecting attendance include a lack of child care, being a single parent, work-related issues, transportation, time conflicts, and gender

\footnotetext{
${ }^{1}$ Department of Nutrition, University of California at Davis, Davis, CA

${ }^{2}$ Department of Internal Medicine, School of Medicine, University of California at Davis, Davis, CA

${ }^{3}$ Center for Transnational Health, University of California at Davis, Davis, CA

${ }^{4}$ Health Science Research Institute, University of California at Merced, Merced, CA

${ }^{5}$ Betty Moore School of Nursing, University of California at Davis, Davis, CA

${ }^{6}$ School of Public Health, University of California at Berkeley, Berkeley, CA

Conflict of Interest Disclosure: The authors have not stated any conflicts of interest.

Address for correspondence: Lucia L. Kaiser, PhD, RD, Department of Nutrition, 1 Shields Ave, University of California-Davis, Davis 95616, CA; Phone: (530) 400-2573; E-mail: 11kaiser@ucdavis.edu

(C) 2018 Society for Nutrition Education and Behavior. Published by Elsevier Inc. All rights reserved.
}

https://doi.org/10.1016/j.jneb.2018.05.004

roles. ${ }^{10}$ Greater motivation, knowledge, participant-facilitator trust, and group cohesion are positively related to attendance. ${ }^{7,10}$

Given the sensitive nature of confronting childhood obesity, research examining psychosocial factors for attendance may help educators plan more effective outreach to high-risk groups. The Theory of Planned Behavior (TPB) has been used to examine predictors of intention and nutrition behavior change. ${ }^{11}$ The TPB may also be useful to identify factors influencing attendance. The objective of this study was to examine factors related to attendance of Mexican-heritage parents at childhood obesity prevention classes. Informed by TPB, the authors hypothesized that constructs influencing attendance included attitudes about learning and being in a class, subjective norms reflecting family and health provider encouragement to attend, and perceived control or beliefs about conditions that enable 
or pose barriers to one's attendance. Health motivation, income, age, acculturation, education, marital status, and employment were also expected to explain attendance. ${ }^{6-10}$

\section{METHODS}

Niños Sanos Familia Sana (Healthy Children, Healthy Families) (NSFS) was a childhood obesity intervention that used a community-based, participatory research approach in a Mexican-heritage audience. ${ }^{12}$ Local Spanish-speaking promotoras (lay workers) helped with recruitment, community events, and classes. Along with free nutrition education classes, NSFS provided participants with vouchers worth $\$ 25 /$ mo to buy produce at a local store. Their children received school-based nutrition education and physical activity programs. Eligibility requirements included (1) having at least 1 child aged $3-7$ years by January 15,2012 ; (2) being of Mexican-heritage, as reported by at least 1 parent; and (3) residing in 1 of 2 selected school districts in California's rural Central Valley. Eligible parents or legal guardians of children gave consent, as approved by the University of California at Davis Institutional Review Board. During the consent process, researchers informed participants that the intervention aimed to prevent childhood obesity. This article examines the attendance of intervention participants during the first 2 years of nutrition classes.

\section{Family Nutrition Education and Attendance}

Nutritionists and local staff developed a culturally adapted childhood obesity prevention curriculum. ${ }^{13}$ For the first 2 years of the intervention, a bilingual, local, Mexican-heritage educator facilitated the classes, covering a different topic each month to groups of 9-15 parents. The study offered classes on multiple occasions each month at 2 local sites; free child care was provided. Both sites were within walking distance (5- to 10minute drive) from most dwellings. The staff planned classes to avoid conflicts with holidays and community events such as food distribution days. Promotoras phoned participants to schedule their preferred class day and time.

During the first year, participants were encouraged to attend at least 5 classes to receive the monthly voucher. There was no attendance goal after the first year. Instead, staff encouraged participants to attend as many sessions as possible to gain knowledge that would help their children. At the end of each month, participants in the classes were eligible to win a raffle basket of household items. Promotoras made reminder calls to participants the day before classes, maintained an attendance $\log$, and assisted the educator with activities. The educator entered attendance data into Excel (version 14.07197.5000, Microsoft Corp, Redmond, WA, 2010).

Because the project had ongoing enrollment over the 2 years (2012-2014), the number of classes that a participant could attend varied. The maximum number of classes was 9 and 8 for the first and second years of the study, respectively. Relative attendance was determined by calculating the ratio of classes attended to the total classes offered during that participant's time in the study. ${ }^{8}$ Median relative attendance among participants was 0.57 for year 1 and 0.63 for year 2. After pooling the 2 years and determining the median of the entire distribution, participants with a relative attendance greater than the median were classified as high-attendance. Those with relative attendance below the median were classified as low-attendance participants. Participants who completed orientation and received vouchers but attended no classes were labeled no-attendance. Dropouts were not included in the analysis because they did not complete orientation, receive vouchers, or attend classes.

\section{Data Collection and Analysis}

Starting in 2011, bilingual researchers who were not involved in delivery of the classes collected baseline data on education, acculturation, marital status, employment, hours spent working outside the home, and other socioeconomic variables. ${ }^{12}$
Interviews took place in homes, the field office, or schools, and in participants' preferred language (English or Spanish). Researchers also measured and weighed participants following standardized procedures. ${ }^{12}$ Based on the Brief Acculturation Rating Scale for Mexican Americans, the Mexican subscale was subtracted from the Anglo subscale to obtain a continuous score. ${ }^{14} \mathrm{~A}$ negative score indicated lower acculturation.

At the exit interview in 2015, the researchers used 8 items, informed by $\mathrm{TPB},{ }^{11}$ to examine psychosocial factors explaining attendance. Because participants were informed during consent that the intervention aimed to prevent childhood obesity, 2 items asked about health motivations. One author pilot-tested the questions among local staff and promotoras $(n=10)$, probing to identify all barriers to attendance regardless of participation level. Table 1 shows the final questions with a 5-response Likert scale. Factor analysis with varimax rotation (version 9.3, SAS, SAS Institute, Cary, NC, 2010) revealed 3 factors related to attitudes and subjective norms, perceived control, and health motivations, supporting construct validity but not strictly aligned with TPB. Cronbach $\alpha$ scores for items that loaded strongly (>.45) on the 3 factors suggested good internal consistency (scores $>.7$ ). ${ }^{15}$ Three scales, which were created by summing the items that loaded strongly on each factor, were used in the subsequent analyses.

The researchers used Stata MP (version 14.1, Stata Corp LP, College Station, TX, 2016) for data analyses. In the bivariate analyses with continuous variables, ANOVA or KruskalWallis test (if there was a nonnormal distribution) was used to compare 3 groups (high, low, or no attendance). Chi-square was used for categorical variables. Significance was $P<.003$ using Bonferroni correction. In post $h o c$ analyses, a significant difference in group means and homogeneity of variances among groups warranted use of Tukey's Honestly Significant Difference test. If variances were not homogeneous, either the GamesHowell or 2-sample proportion test was used. Stepwise regression was used to select the best variables 
Table 1. Factor Analysis of Psychosocial Variables Explaining Attendance Among Mexican-Heritage Parents, 2015 $(n=212)$

\begin{tabular}{|c|c|c|c|}
\hline Variables & $\begin{array}{c}\text { Factor } 1 \\
\text { (Perceived } \\
\text { Control) }\end{array}$ & $\begin{array}{c}\text { Factor } 2 \\
\text { (Attitudes/ } \\
\text { Subjective } \\
\text { Norms) }\end{array}$ & $\begin{array}{c}\text { Factor } 3 \\
\text { (Health } \\
\text { Motivation) }\end{array}$ \\
\hline $\begin{array}{l}\text { 1. I attended nutrition classes because I wanted to learn something that } \\
\text { benefits my child(ren). }\end{array}$ & 0.102 & 0.893 & 0.232 \\
\hline $\begin{array}{l}\text { 4. I attended nutrition classes because other family members encouraged me } \\
\text { to go. }\end{array}$ & 0.094 & 0.572 & 0.380 \\
\hline 5. I attended nutrition classes because my child was overweight. & 0.118 & 0.134 & 0.841 \\
\hline 8. Nutrition classes were not offered at a convenient location for me. & 0.893 & 0.119 & 0.080 \\
\hline 9. Nutrition classes were not offered at a convenient time for me. & 0.878 & -0.063 & 0.127 \\
\hline 10. Taking care of my children made it too difficult for me to attend class. & 0.752 & 0.034 & 0.132 \\
\hline Eigenvalue & 3.7 & 2.2 & 1.2 \\
\hline Cronbach $\alpha$ for bolded variables & .82 & .82 & .78 \\
\hline
\end{tabular}

Notes: Data are derived from a factor analysis with varimax rotation. Values are bolded if loading is $>0.45$. Items are based on a 5-response Likert scale in which $1=$ not at all like me and $5=$ very much like me. Expected theoretical constructs are attitudes (1 and 2), subjective norms (3 and 4), health motivation (5 and 6), and perceived control (7-10).

among those that were strongly correlated. Multivariable ordinal logistic regression analysis was employed to model the correlates of attendance, using covariates from the bivariate analyses or literature ${ }^{7-10}$ in model 1 , and in model 2 , both covariates and TPB constructs.

\section{RESULTS}

Of 334 participants who gave consent and completed baseline interviews, 64 (19\%) dropped out of the program. The final sample consisted of $50 \% \quad(n=134)$ with high attendance, $26 \%(n=70)$ with low attendance, and $24 \%(\mathrm{n}=66)$ with no attendance. Participants were primarily born in Mexico (75\%; 199) and had an income less than $185 \%$ of the federal poverty level (88\%; 237). Their mean (SD) age was 33.5 (7.0) years. Half of all mothers (51.6\% [99]) had a body mass index (BMI) > $30 \mathrm{~kg} / \mathrm{m}^{2}$. Among their children, $45.9 \%$ (122) had a BMI > 85th percentile. There were no differences (data not shown) between dropouts and the other groups for any characteristics.

The relationships of TPB constructs and covariates to the outcome (attendance) are displayed in Table 2 (bivariate analyses) and Table 3 (multivariable ordinal logistic regression) and Supplementary Data. Highattendance mothers were significantly older and less acculturated than were low- and no-attendance mothers $(P=.001)$ (Table 2$)$. Highattendance mothers also reported more positive attitudes and norms related to attendance than did lowor no-attendance mothers $(P=.001)$. No significant differences owing to perceived control or health motivations were observed. Neither child's weight nor parent's perception of child's weight influenced attendance (Supplementary Data). Attitudes and norms were independently related to attendance, controlling for mother's age, acculturation, and other covariates (odds ratio $=1.27 ; 95 \%$ confidence interval [CI], 1.18-1.37; $P<$.001) (Table 3).

\section{DISCUSSION}

In these rural Mexican-heritage families, attitudes related to learning and interacting with other mothers in classes and norms indicating stronger support at home were independently related to high, low, or no attendance after controlling for mother's age, acculturation, and marital status.

The results were generally congruent with other studies. In a 30-session parenting skills intervention targeting Latino and black families of adolescents, $20 \%$ of the adults were nonattenders and $33.6 \%$ were highattenders compared with $24 \%$ and $50 \%$, respectively, in the NSFS study. $^{8}$ Other researchers reported positive associations between attendance and older maternal age, marital status, family support, and group 
Table 2. Bivariate Analysis of Variables Related to Attendance of Mexican-Heritage Parents

\begin{tabular}{|c|c|c|c|c|}
\hline Relative Attendance & High $(n=134)$ & Low $(n=70)$ & No $(n=66)$ & $\boldsymbol{P}$ \\
\hline Mother's age, y (mean [SD]) $(n=269)^{\star}$ & $35.2(7.0)^{\mathrm{a}}$ & $32.4(7.1)^{\mathrm{b}}$ & $31.1(6.0)^{b}$ & .001 \\
\hline Mother born in Mexico, $n(\%)(n=267)^{\star \star}$ & $111(84 \%)^{\mathrm{a}}$ & $44(64 \%)^{a}$ & $44(67 \%)^{a}$ & .002 \\
\hline Mother married, $n(\%)(n=256)^{\star \star}$ & $96(73 \%)^{a}$ & $36(56 \%)^{a}$ & $28(48 \%)^{a}$ & .002 \\
\hline Maternal acculturation score, median (IQR) $(n=266)^{\star \star \star}$ & $-2.83(1.67)^{\mathrm{a}}$ & $-1.33(3.16)^{b}$ & $-1.67(3.40)^{b}$ & .001 \\
\hline Spoke primarily Spanish at home, $n(\%)(n=265)^{\star \star}$ & $105(80 \%)^{a}$ & $38(55 \%)^{b}$ & $39(60 \%)^{a}$ & .001 \\
\hline Weekly work outside home, h, median (IQR) $(n=256)^{\star \star \star}$ & $0.0(40.0)$ & $35.0(40.0)$ & $32.5(40.0)$ & .040 \\
\hline Attitudes and subjective norms, median (IQR) $(n=212)^{\star \star \star}$ & $11.0(2.0)^{\mathrm{a}}$ & $11.0(10.0)^{\mathrm{b}}$ & $3.0(8.0)^{\mathrm{b}}$ & .001 \\
\hline Perceived control, median (IQR) $(n=212)^{\star \star \star}$ & $6.0(4.0)$ & $4.0(4.0)$ & $4.0(4.0)$ & .140 \\
\hline Health motivations, median (IQR) $(n=212)^{\star \star \star}$ & $6.0(4.5)$ & $5.0(4.0)$ & $3.0(3.0)$ & .008 \\
\hline
\end{tabular}

IQR indicates interquartile range.

${ }^{*}$ Analysis of variance; ${ }^{* \star}$ Chi-square test; ${ }^{* \star *}$ Kruskal-Wallis test.

Notes: Relative attendance is the proportion of log-recorded attendance to total nutrition classes offered. Significant group differences are denoted in superscripts with different letters. Significance is at $P<.003$ (with Bonferroni correction).

cohesion. $^{7-9}$ In this study, participants who found learning and being with other parents to be enjoyable (attitude) and reported encouragement from family members to attend (norms) were more likely to attend classes. Although TPB posits that attitudes and norms are distinct constructs, it is unsurprising that these constructs were correlated in a rural audience seeking social interaction. Perceived control related to convenience of class location and times and availability of child care were not significant. Possibly, these barriers were minimal compared with other studies ${ }^{10}$ or these items did not truly capture the TPB construct of perceived control. In a study of college students, both attitudes and perceived control predicted fitness center attendance. ${ }^{16}$

Taught by a bilingual educator, NSFS parent classes were culturally sensitive and focused on the needs of less-acculturated, low-income, rural families. The multivariate analysis suggested that acculturation effects may be partly explained by attitudes and norms related to attending nutrition classes. Previous quantitative studies of attendance among Latinos did not examine acculturation. ${ }^{7,8}$ Although other authors reported higher income and lower maternal BMI to be positively related to attendance, ${ }^{5,8}$ neither income nor BMI predicted attendance here. In this study, most mothers were lowincome and/or overweight, giving little variation in these variables.

A strength of this study was applying TPB to examine attendance in a rural, low-income, Mexican-heritage population at high risk for childhood obesity. Consistency in program delivery using trusted, local, bilingual staff allowed for observation of attendance over 2 years.

Limitations included assessing TPB variables only at the end of the study and having a homogeneous sample, which made it difficult to examine the effects of demographic

Table 3. Multivariate Ordinal Logistic Regression Examining Factors Related to High, Low, or No Relative Attendance Among Mexican-Heritage Parents $(n=194)$

\begin{tabular}{|c|c|c|c|c|}
\hline \multirow[b]{2}{*}{ Variable } & \multicolumn{2}{|c|}{ Model 1} & \multicolumn{2}{|c|}{ Model 2} \\
\hline & Odds Ratio & $95 \% \mathrm{Cl}$ & Odds Ratio & $95 \% \mathrm{Cl}$ \\
\hline Maternal age & 1.06 & $1.01-1.11$ & 1.07 & $1.02-1.13$ \\
\hline Mother married & 1.70 & $0.90-3.19$ & 1.43 & $0.74-2.75$ \\
\hline Maternal education, y & 1.05 & $0.96-1.16$ & 1.04 & $0.95-1.15$ \\
\hline Maternal acculturation & 0.84 & $0.68-1.03$ & 0.86 & $0.70-1.07$ \\
\hline Weekly work, h & 0.98 & $0.97-0.99$ & 0.98 & $0.97-1.00$ \\
\hline Attitudes and subjective norms & NA & $N A-N A$ & 1.27 & $1.18-1.37$ \\
\hline Akaike information criterion & \multicolumn{2}{|c|}{366.8} & \multicolumn{2}{|c|}{331.5} \\
\hline Akaike information criterion/n & \multicolumn{2}{|c|}{1.89} & \multicolumn{2}{|c|}{1.71} \\
\hline
\end{tabular}

Notes: Relative attendance is the proportion of log-recorded attendance to the total number of nutrition classes offered. For the Akaike information criterion, lower values indicate a better model fit. 
factors on attendance. Test-retest reliability was not evaluated. However, the content and wording of the TPB items were tailored to this audience and resulted in good internal consistency. Further cognitive testing and validation of items are needed.

\section{IMPLICATIONS FOR RESEARCH AND PRACTICE}

This study adds to the literature by examining the relationship of psychosocial factors, informed by TPB, to attendance of rural Mexicanheritage families at classes offered in a childhood obesity intervention. Attitudes and norms related to class attendance emerged as important in the model and diminished the effect of acculturation on attendance. For practitioners, the implications are that recent immigrants may attend nutrition programs because they seek interactions with other parents facing similar challenges. To reach this audience, programs to prevent childhood obesity may need to provide families with face-to-face interaction. For researchers, application of TPB to explain attendance is promising but further development and rigorous testing of instruments are needed. Examining attitudes and norms related to participation may yield insights about subgroups who respond more strongly to childhood obesity interventions.

\section{ACKNOWLEDGMENTS}

The authors acknowledge Marcel Horowitz, Karina Rios, Dorina Espinoza, and Judith Martinez. This material is based on work supported by the National Institute of Food and Agriculture, US Department of Agriculture, under Award No. 201168001-30167. Any opinions, findings, conclusions, or recommendations expressed in this publication are those of the authors and do not necessarily reflect the view of the US Department of Agriculture.

\section{SUPPLEMENTARY DATA}

Supplementary data related to this article can be found at https://doi. org/10.1016/j.jneb.2018.05.004.

\section{References}

1. Ogden CL, Carroll MD, Lawman HG, et al. Trends in obesity prevalence among children and adolescents in the United States, 1988-1994 through 2013-2014. JAMA. 2016;315:22922299.

2. Hartman MA, Hosper K, Stronks K. Targeting physical activity and nutrition interventions towards mothers with young children: a review on components that contribute to attendance and effectiveness. Public Health Nutr. 2011; 14:1364-1381.

3. Branscum P, Sharma M. A systematic analysis of childhood obesity prevention interventions targeting Hispanic children: lessons learned from the previous decade. Obes Rev. 2011;12:e151e158.

4. Barkin SL, Gesell SB, Po'e EK, Escarfuller J, Tempesti T. Culturally-tailored, family-centered, behavioral obesity intervention for Latino-American preschool-aged children. Pediatrics. 2012; 130:445-456.

5. Atkins CJ, Senn K, Rupp J, et al. Attendance at health promotion programs: baseline predictors and program outcomes. Health Educ Q. 1990;17: 417-428.

6. Havas S, Anliker J, Greenberg D, et al. Final results of the Maryland WIC food for life program. Prev Med. 2003;37: 406-416.

7. Prado G, Pantin H, Schwartz SJ, Lupei NS, Szapocznik J. Predictors of engagement and retention into a parent-centered, ecodevelopmental HIV preventive intervention for Hispanic adolescents and their families. J Pediatr Psychol. 2006;31:874-890.
8. Coatsworth JD, Duncan LG, Pantin H, Szapocznik J. Patterns of retention in a preventive intervention with ethnic minority families. J Prim Prev. 2006; 27:171-193.

9. Damron D, Langenberg P, Anliker J, Ballesteros M, Feldman R, Havas S. Factors associated with attendance in a voluntary nutrition education program. Am J Health Promot. 1999;13: 268-275.

10. Garcia-Huidobro D, Allen M, RosasLee $M$, et al. Understanding attendance in a community-based parenting intervention for immigrant Latino families. Health Promot Pract. 2016;17:57-69.

11. Montaño DE, Kasprzyk. Theory of reasoned action, theory of planned behavior, and the integrated behavioral model. In: Glanz K, Rimer BK, Viswanath K, eds. Health Behavior and Health Education: Theory, Research, and Practice. 4th ed. San Francisco, CA: Jossey-Bass; 2008:67-96.

12. de la Torre A, Sadeghi B, Green RD, et al. Niños Sanos, Familia Sana: Mexican immigrant study protocol for a multifaceted CBPR intervention to combat childhood obesity in two rural California towns. BMC Public Health. 2013;13:1033.

13. Kaiser L, Martinez J, Horowitz M, et al. Adaptation of a culturally relevant nutrition and physical activity program for low-income, Mexican-origin parents with young children. Prev Chronic Dis. 2015;12:E72.

14. Cuellar I, Arnold B, Maldonado R. Acculturation rating scale for Mexican Americans-II: a revision of the original ARSMA scale. Hispanic J Behav Sciences. 1995;17:275-304.

15. Santos JR. Cronbach's alpha: a tool for assessing the reliability of scales. https://www.joe.org/joe/1999april/ tt3.php. Accessed March 19, 2018.

16. Jekauc D, Völkle M, Wagner MO, Mess F, Reiner M, Renner B. Prediction of attendance at fitness center: a comparison between the theory of planned behavior, the social cognitive theory, and the physical activity maintenance theory. Front Psychol. 2015;6:121. 